\title{
Recent Changes to the Federal Reserve's Survey of Terms of Business Lending
}

Thomas F. Brady, William B. English, and William R. Nelson, of the Board's Division of Monetary Affairs, prepared this article. Thomas C. Allard assisted in the preparation of the data. Lisa X. Chen and Adrian R. Sosa provided research assistance.

The Federal Reserve's quarterly Survey of Terms of Business Lending, which has been conducted for more than twenty years, collects information on interest rates and other characteristics of commercial bank loans to businesses. The survey has been changed from time to time to recognize innovations in bank lending practices and to improve the measurement of the desired information. The most recent changes took effect with the May 1997 survey. ${ }^{1}$ The major improvement was the addition of an item measuring loan risk. The addition of this item was possible because a large and increasing percentage of banks have adopted the practice of assigning internal risk ratings to their "pass" loans-that is, loans other than those to troubled borrowers. (Loans to troubled borrowers are generally part of workout arrangements.) Further changes were made to the survey to improve the measurement of other important loan characteristics. In addition, the reporting panel, which had been limited to domestically chartered commercial banks, was expanded to include a sample of U.S. branches and agencies of foreign banks. These branches and agencies now account for a significant proportion of business lending to U.S. firms. ${ }^{2}$

1. Details on the proposed changes to the survey were published for public comment in Board of Governors of the Federal Reserve System, "Agency Information Collection Activities: Proposed Collection; Comment Request," Federal Register, vol. 61 (July 23, 1996), pp. 38202-203. Announcement of the final Board action was published in Board of Governors of the Federal Reserve System, "Agency Information Collection Activities: Submission to OMB Under Delegated Authority," Federal Register, vol. 61 (October 24, 1996), pp. 55151-152.

Changes like those made to the business survey were made at the same time to a survey of farm loans (Survey of Terms of Bank Lending to Farmers).

2. As a result of the inclusion of the branches and agencies of foreign banks, the name of the survey was changed from the Survey of Terms of Bank Lending to Business to the Survey of Terms of Business Lending. In this article we refer to both the old and new versions of the survey as the STBL.
This article discusses the most recent changes made to the survey and presents some information now available from the new items being reported. It also summarizes information about the use of loan risk ratings from consultations with a sample of the survey respondents. These consultations were conducted in the process of planning the revisions to the survey and provided much useful information, particularly with respect to risk ratings.

\section{BACKGROUND OF THE SURVEY}

Since its inception in 1977, the Survey of Terms of Business Lending (STBL) has provided unique information concerning the terms (both price and nonprice) of commercial and industrial loans made to U.S. nonfinancial businesses by commercial banks. The STBL replaced the Quarterly Interest Rate Survey and portions of the Survey of Selected Interest Rates. It was designed to provide more accurate and detailed information than these surveys on business loans, especially concerning maturity and nonprice terms. (See the box, "A History of Federal Reserve Surveys of Business Lending Terms.")

The STBL collects detailed data on individual loans from a stratified random sample of about 300 institutions. The survey respondents provide information on the stated rate of interest on each loan extended during the survey week and the frequency with which interest is compounded or paid, thereby allowing calculation of the effective interest rate. The respondents also report other important loan characteristics, including loan size, loan maturity, the frequency of repayments, collateralization status, and the size of the commitment (if any) under which the loan was extended.

Data are collected for the first full business week of the middle month of each quarter (February, May, August, and November). These sample data are used to construct estimates of the terms of business loans extended during the reporting week at all domesti- 
cally chartered commercial banks and U.S. branches and agencies of foreign banks. ${ }^{3}$

3. These estimates are published in the Federal Reserve Bulletin and in the Federal Reserve's E.2 Statistical Release, "Survey of Terms of Business Lending," which is available on the Board's web site (www.bog.frb.fed.us/releases/E2). The results of the most recent

\section{RECENT CHANGES TO THE SURVEY}

The most recent changes to the survey involved the addition of items on loan risk, the introduction of other new items, the revision or deletion of some items, and an expansion of the coverage of the survey.

survey, conducted in May, are published in this issue of the Bulletin on pages A67-A71.

\section{A History of Federal Reserve Surveys of Business Lending Terms}

The Federal Reserve has collected and published information on business loan rates at commercial banks since 1919 . Between 1919 and 1939 the Federal Reserve collected monthly data on the average prevailing rate charged on prime (high-quality) commercial loans as part of its survey of rates on loans to customers. By 1930 the survey included about 200 large banks in thirty-six "principal" cities, although the panel had been smaller in earlier years. Calculations of the published estimates of regional and national average rates were based on the volume of lending at the surveyed banks and at other large banks.

One problem with this survey was that rather than providing information on the average rate actually paid by all business borrowers, it covered only the rate paid by prime borrowers, which tended to be relatively large. In 1939 the Federal Reserve introduced a new survey (the Quarterly Interest Rate Survey, or QIRS) and discontinued the previous survey. The new survey collected information from a panel of about ninety large banks in nineteen cities on the distribution of actual loan rates charged on all new commercial and industrial loans with maturities of between thirty days and one year during the first half of the final month of each quarter. This information was used to calculate the weighted-average rate on new business loans at large banks by region and for the nation as a whole. Starting in 1948, the QIRS collected data on the terms of individual loans with maturities of less than one year, and weighted-average rates on such loans were calculated and reported by loan size.

The QIRS was substantially revised in 1967. The panel size was increased to 126 large banks in thirty-five cities. At the same time, the timing of the survey was shifted to the middle month of each quarter. The Federal Reserve continued to publish weighted-average loan rates for loans with maturities of less than one year and provided average rates for more regions and for larger size categories than had been the case before the revisions.

Starting in 1971 and continuing until the survey was discontinued in 1977, separate weighted-average loan rates were published for three types of loan: ${ }^{1}$ term loans (those

1. Data allowing these three rates to be calculated had been collected since 1967. Historical data for the new series were published for 1967-71. See Mary F. Weaver and Edward R. Fry, "Bank Rates on Business LoansRevised Series," Federal Reserve Bulletin, vol. 57 (June 1971), pp. 468-77. with maturities of more than one year), loans made under revolving credit arrangements, and other loans with maturities of less than one year. These rates were published by size category and region as well as for the entire nation.

Starting in January 1972 the Federal Reserve began a monthly survey of interest rates on a variety of bank loans for the Committee on Interest and Dividends (the CID survey). The committee, which was chaired by Federal Reserve Chairman Arthur Burns, was established by Executive Order in October 1971 to formulate and execute a program for voluntary restraint on interest rates and dividends. The CID survey, which was conducted in addition to the QIRS, collected monthly data on selected loan interest rates from a panel of about 350 banks of all sizes. One portion of this survey gathered data on the "most common" rate on small, short-term, noninstallment business loans. Another portion of the survey collected data on the prime rates applicable to small and large business loans. Averages of these rates, calculated on an unweighted basis, were published in a Federal Reserve statistical release.

In 1977 the Federal Reserve replaced the QIRS and the business loan portion of the CID survey with the Survey of Terms of Bank Lending to Business (STBL). The new survey was similar to the QIRS, but the panel of respondents was expanded considerably and included banks of all sizes. The respondents reported the terms on loans extended in the first full business week of the middle month of each quarter. The responses were used to estimate the average rate and terms on all business loans and on loans of various sizes and maturities that were extended by all U.S. commercial banks during the survey week.

Three significant changes to the STBL preceded the current revision. First, in 1982 the reporting of loan maturity was changed from months to days to allow overnight loans, which were becoming much more common at that time, to be detected. Second, starting in 1986 the respondents were asked to report the base rate used in the setting of loan interest rates because banks were increasingly using market rates rather than the prime rate to price business loans. Finally, in 1989 construction and land development loans secured by real estate, which had been included as a separate category on the STBL until that time, were dropped from the survey. 


\section{Adding Information on Loan Risk}

The ability to distinguish among possible reasons for a movement in loan interest rates could contribute to improved monetary policy. If, for example, banks raise or lower loan interest rates for borrowers of unchanged quality, this change could have implications for spending and aggregate demand that would be important in setting monetary policy. Alternatively, a change in the average loan rate resulting from a shift in the composition of bank loans could suggest that banks have modified their lending standards, again with possible implications for monetary policy. For example, a lowering of standards could induce a rise in the average loan rate, as a larger number of risky borrowers received loans at relatively high interest rates.

In the past, however, using the survey data to monitor developments in business loan pricing was hampered by a lack of information on loan risk. For example, when spreads of loan rates over base rates rose sharply in the early 1990s, the increase may have arisen from tighter loan pricing by banks as a result of their desire to limit credit extensions, a worsening of the average quality of new borrowers, or both.

In recent years, an increasing share of banks have assigned internal risk ratings to their business loans. This development provided the Federal Reserve with an opportunity to collect information on banks' assessment of loan riskiness. For this information to be useful, however, three conditions had to be met: First, the proportion of banks assigning risk ratings to new loans reported on the STBL had to be sufficiently large; second, banks had to use more than one rating for acceptable new loans; and, third, the definitions of the ratings had to be independent of the state of the economy.

To determine whether these criteria could be met, Reserve Bank staff members consulted with 114 STBL respondents. Of these, about 85 percent reported assigning risk ratings to new business loans or business borrowers (table 1). ${ }^{4}$ All of the large banks (those with outstanding commercial and industrial loans of more than $\$ 1$ billion) assigned internal risk ratings, and virtually all of the medium-sized banks (commercial and industrial loans between $\$ 100$ million and \$1 billion) did so. Even among the small banks (commercial and industrial loans of less than $\$ 100$ million), about two-thirds reported having a risk rating system. More detailed interviews with personnel from eight STBL respondents indicated that definitions of risk-rating categories did not generally change in the face of changing economic conditions, at least at those institutions.

At most banks, ratings varied enough across loans to make the information provided on loan risk valuable. Most commonly, banks used between three and

4. A bank that had only a single rating for acceptable new loans was not counted as having a rating system.

1. Information on domestic banks' internal rating systems for business loans, by size of bank, November 1995

\begin{tabular}{|c|c|c|c|c|}
\hline Item & All & Large & Medium & Smal \\
\hline Percentage rating either loans or borrowers . & 85.1 & 100.0 & 94.1 & 68.8 \\
\hline 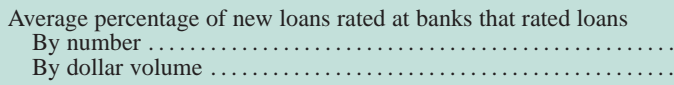 & $\begin{array}{l}95.2 \\
96.6\end{array}$ & $\begin{array}{l}97.4 \\
98.0\end{array}$ & $\begin{array}{l}93.9 \\
95.9\end{array}$ & $\begin{array}{l}94.5 \\
95.8\end{array}$ \\
\hline 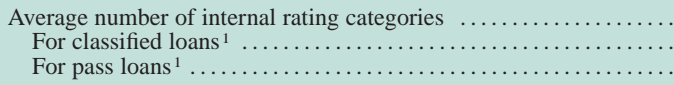 & $\begin{array}{l}7.79 \\
3.70 \\
4.00\end{array}$ & $\begin{array}{l}8.66 \\
3.63 \\
4.77\end{array}$ & $\begin{array}{l}7.56 \\
4.00 \\
3.77\end{array}$ & $\begin{array}{l}7.18 \\
3.48 \\
3.43\end{array}$ \\
\hline $\begin{array}{l}\text { Average number of rating categories, with each having } 10 \text { percent } \\
\text { or more of the dollar volume of new loans } \ldots \ldots \ldots \ldots \ldots \ldots \ldots\end{array}$ & 2.49 & 3.04 & 2.22 & 2.24 \\
\hline $\begin{array}{l}\text { Percentage of banks with } 75 \text { percent or more of the dollar volume } \\
\text { of new loans in one rating category ............................... }\end{array}$ & 37.7 & 12.0 & 47.8 & 51.7 \\
\hline $\begin{array}{l}\text { Average share of new loan volume in the rating category } \\
\text { with the largest share } \ldots \ldots \ldots \ldots \ldots \ldots \ldots \ldots \ldots \ldots\end{array}$ & 64.8 & 53.6 & 68.4 & 71.6 \\
\hline $\begin{array}{l}\text { Average rating category assigned to a borrower with } \\
\text { an unsecured bond rating of } \mathrm{BBB}^{2} \ldots \ldots \ldots \ldots .\end{array}$ & 3.29 & 3.66 & 2.96 & 3.20 \\
\hline $\begin{array}{l}\text { MEмо } \\
\text { Number of respondents } \ldots \ldots \ldots \ldots \ldots . . . .\end{array}$ & 114 & 32 & 34 & 48 \\
\hline
\end{tabular}

NoTE. The data were compiled from consultations with 114 respondents to the STBL. These consultations were conducted to collect information to be used in deciding on the revisions to the survey. The size of bank is based on the volume of commercial and industrial loans on the bank's books as of Septem-

ber 30, 1995: For large banks, more than \$1 billion; medium-sized banks, between $\$ 100$ million and $\$ 1$ billion; and small banks, less than $\$ 100$ million. 1. For definition, see text.

2. On an ascending scale in which 1 is the rating with the lowest risk. 
five ratings for new pass loans, with larger banks having more pass ratings on average. Although in practice most banks assigned the bulk of their loans to a smaller number of rating categories, they generally placed at least 10 percent of new loans in each of two or three rating categories. Many banks also assigned smaller, but still significant, proportions of new loans to another one or two rating categories. Small banks tended to assign their loans to fewer rating categories. Indeed, more than half of the small banks indicated that they assigned the same rating to 75 percent or more of their new loans, while only 12 percent of the large banks did so.

The substantial differences among the rating systems of different banks posed a major obstacle to the collection on the STBL of useful information on loan risk. Some of the banks included in the consultations used only one pass rating, while others had as many as eleven. Even banks that used the same number of ratings were likely to have differing definitions of the individual categories. In addition, banks labeled the categories in different ways, some with numbers, others with letters, and a few with a mix of numbers and letters. Although most banks had adopted the convention that a rating of 1 represented the lowest risk, a small number of banks used that number for their highest risk category.

Given these differences, it was necessary to map the risk ratings of each respondent into a single system. Two approaches for this mapping procedure were considered. Under the first, the Federal Reserve would collect and maintain a concordance for each respondent, showing how that respondent's risk ratings mapped into a common rating system. Alternatively, the respondents would do the mapping themselves before submitting their data.

The first method appeared to be impractical, whereas the second offered some advantages. Under the first method, Federal Reserve staff members would have had to gather and maintain a considerable amount of information on each respondent's rating system to make the translations. In addition, banks that had recently merged might have more than one rating system, and so for these respondents the rating system applied to each loan would have to be identified. In contrast, under the second method, banks would likely find it easier to construct concordances themselves rather than provide descriptions of their risk ratings in sufficient detail to allow the Federal Reserve staff to construct them. Similarly, although changes in a bank's rating system over time would require an adjustment to the concordance, the bank would not need to provide information about such changes to the Federal Reserve.
With these considerations in mind, the Federal Reserve decided on the second method: The survey asks respondents to translate their internal ratings into one of five rating categories provided in the survey instructions, including four pass categories: "minimal risk," "low risk," "moderate risk," and "acceptable risk." The moderate-risk category is defined to cover the average loan under average economic conditions at the typical bank. The fifth rating is a "classified" category for risky loanslikely part of workout arrangements for troubled borrowers - that the respondents judge belong in the examination categories "special mention," "substandard," "doubtful," or "loss." 5 The survey also allows for unrated loans because some of the banks consulted indicated that they did not usually rate some types of business loans, most often those to small businesses.

\section{Other New or Revised Items}

A second important change to the survey was designed to allow an assessment of the sensitivity of loan rates to changes in market rates and to improve the Federal Reserve's ability to match loan rates to market rates of an appropriate maturity when calculating spreads. To accomplish these aims, banks are asked to report the first date on which rates on variable-rate loans are scheduled to adjust. (Frequently, loans are priced so that the interest rate adjusts at specified intervals over the life of the loan, typically with respect to market rates such as those on large time or Eurodollar deposits.)

The revised survey also asks banks to provide more information about the options available to terminate a loan. Previously, the survey addressed this concept by asking respondents to classify a loan as a "demand loan" if the bank had the right to call it (that is, demand immediate repayment) or renegotiate its terms at any time. Loans were also classified as demand loans if the borrower had the option to prepay it without cost (that is, without a prepayment penalty or "breakage fee"). Banks were instructed to identify demand loans by leaving the reported maturity date blank. This reporting method resulted in the loss of maturity information for demand loans and provided no information on whether the option to terminate the loan belonged to the borrower, the bank, or both. In contrast, the revised survey asks

\footnotetext{
5. The appendix contains the definitions of the risk-rating categories as presented in the survey instructions.
} 
banks to report the date of maturity for every loan having a stated maturity and to report separately whether the loan can be called and whether it has a prepayment penalty.

\section{Items Dropped from the Survey}

Two items were dropped from the survey as of May 1997. One asked banks to report the size of the larger loan syndication or participation, if any, of which a reported loan was a part. This information applied to only a small share of loans, and many banks had noted that it was difficult to provide. The other item asked banks whether the commitment under which a loan was extended was formal or informal. This item was dropped because some banks found it difficult to report and because the increased use of informal credit lines by high-quality firms blurred the distinction between the two types of commitments.

\section{Expansion of the Survey Panel}

Until the most recent revision, the STBL panel consisted entirely of domestic banks. ${ }^{6}$ However, since the inception of the STBL, the share of the volume of all U.S. domestic business loans held by U.S. branches and agencies of foreign banks has increased from about 7 percent to about 25 percent (chart 1). As a result, the exclusion of these institutions from the STBL panel resulted in a progressively less representative measure of business loan conditions in the United States because lending terms at foreign branches and agencies may be influenced by foreign developments that do not directly affect domestic institutions. To remedy this shortcoming, the survey was expanded to include a sample of up to fifty U.S. branches and agencies of foreign banks. Collection of information from these institutions allows the estimation and publication (in the Federal Reserve Bulletin and in the E.2 statistical release) of separate estimates of terms on loans extended in the United States by foreign branches and agencies.

Two criteria were used in the selection of the panel institutions from the universe of more than 450 U.S. branches and agencies of foreign banks: the institution's size and the nationality of its parent bank. Because larger institutions make more and larger loans than smaller institutions, they have a larger

6. Currently, the domestic panel consists of a stratified random sample of up to 348 U.S. commercial banks intended to represent the entire domestic banking universe.
1. Share of U.S. business loans held by U.S. branches and agencies of foreign banks, 1977-May 1998

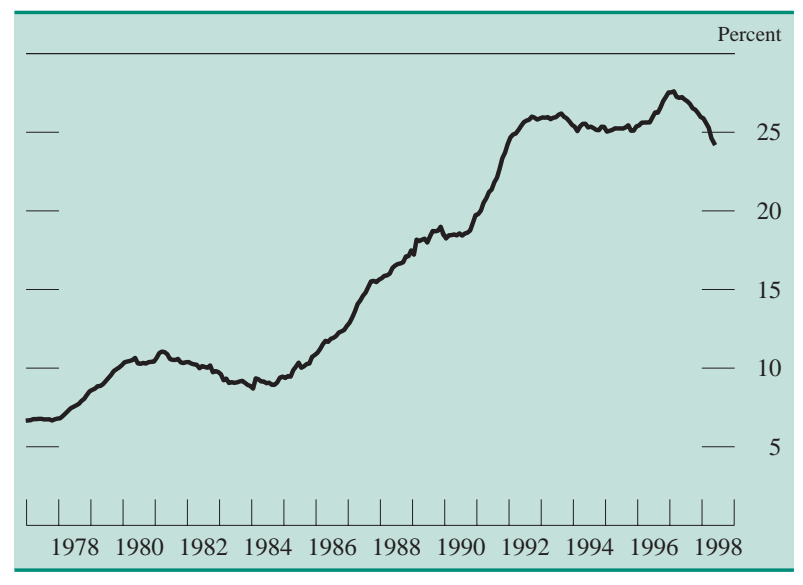

Note. The data are monthly.

effect on the rates, maturities, and other loan terms available in the market. The nationality of the parent bank was considered important because evidence from the Report of Assets and Liabilities of U.S. Branches and Agencies of Foreign Banks (FFIEC 002) indicates that the behavior of the balance sheet items of U.S branches and agencies of Japanese banks can differ significantly from that of non-Japanese (primarily European) institutions.

The classification of the panel by size and nationality resulted in five groups. The first group comprised the fifteen largest foreign branches and agencies (regardless of nationality), as measured by the volume of commercial and industrial loans outstanding. All of these institutions were selected for inclusion in the panel. The remaining universe of institutions was then split into two size classes, large and small, and the two size classes were split into Japanese and non-Japanese subclasses; the remaining panel institutions were then selected randomly from these four groups. The number of panel members selected from each of the four groups was chosen to provide the best possible estimates of loan terms at all foreign institutions. $^{7}$

\section{PRELIMINARY RESULTS FROM THE REVISED SURVEY}

Although the new items should have their main payoff in helping to explain changes in loan pricing over

7. About thirty of the fifty institutions originally selected for the foreign panel participated in the May 1998 survey. Some of the others have been unable to participate thus far but have indicated that they will be able to report on future surveys. When selected institutions are unable to participate, new panel members are substituted. 
time, the results from the initial surveys incorporating the revisions have also provided interesting information on risk ratings and pricing patterns for loans and their relationship to capital market spreads.

\section{Reporting of Loan Risk Ratings}

In the May 1998 survey, nearly 85 percent of the domestic respondents and more than 95 percent of the foreign branches and agencies reported risk ratings for some or all of their loans (table 2). Among the domestic banks, medium-sized banks were most likely to provide ratings, but the differences by size of bank were small compared with those found in the consultations. The explanation for this divergence may be that some small banks without internal risk ratings used the definitions provided in the STBL instructions to rate the small number of loans they made in the survey week. Moreover, some large banks that do have internal risk ratings may not be able to provide ratings on the survey because automated systems are not yet in place for this survey or have not been updated to incorporate the changes to the survey. Because of the large number of loans reported by the larger respondents, providing risk ratings manually may be prohibitively expensive.

Those banks that reported risk ratings in the May survey provided them for nearly all-
$98 \frac{1}{2}$ percent- of the loans they reported. A second divergence between the consultations and the STBL results was that small loans appeared to be almost as likely to receive a rating as large loans. This difference may reflect increased efforts to apply ratings, or it may arise from improvements in technology since the consultations took place that allow ratings to be assigned to these loans at lower cost.

Consistent with the results of the consultations was the finding that a respondent's loans tended to be concentrated in relatively few of the STBL rating categories, especially at the smaller domestic banks. The number of rating categories receiving more than 10 percent of new loans averaged 2.5 for the large domestic banks but just 1.5 for the small banks. Similarly, while one-fifth of the large banks gave the same rating to 75 percent or more of new loans (by dollar volume), about half of the medium-sized banks and two-thirds of the small banks did so. As might be expected, given that the parent institutions of the foreign branches and agencies are generally fairly large, the distributions of their ratings were similar to those of the larger domestic banks. On average, the foreign branches and agencies had 2.2 categories, each with at least 10 percent of new extensions; only 31 percent of them assigned 75 percent or more of the dollar volume of new loans to a single risk class.

2. STBL results for risk ratings, by type of institution, May 1998

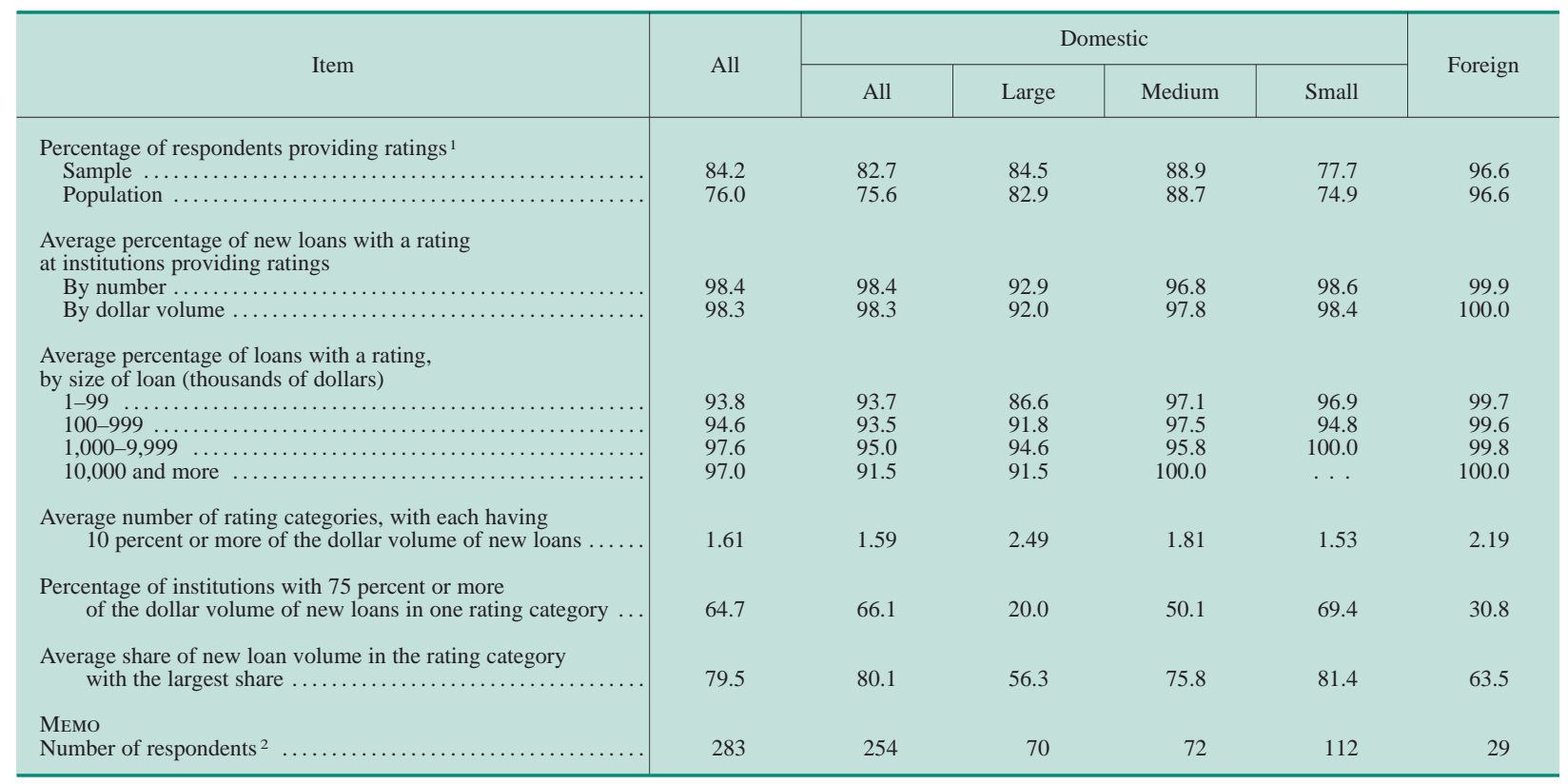

Note. The size categories for domestic banks are based on the volume of commercial and industrial loans on the bank's books as of December 31, 1997;

1. The sample figures show unweighted results for the survey respondents. see the general note to table 1 for categories. Other figures are estimates for the population of all domestically chartered commercial banks and U.S. branches and agencies of foreign banks.

2 . In addition, 24 respondents, mostly small domestic banks, had no new business loans in the survey week. 
2. Distribution of loan originations and average interest rates, by risk rating, May 1998 STBL

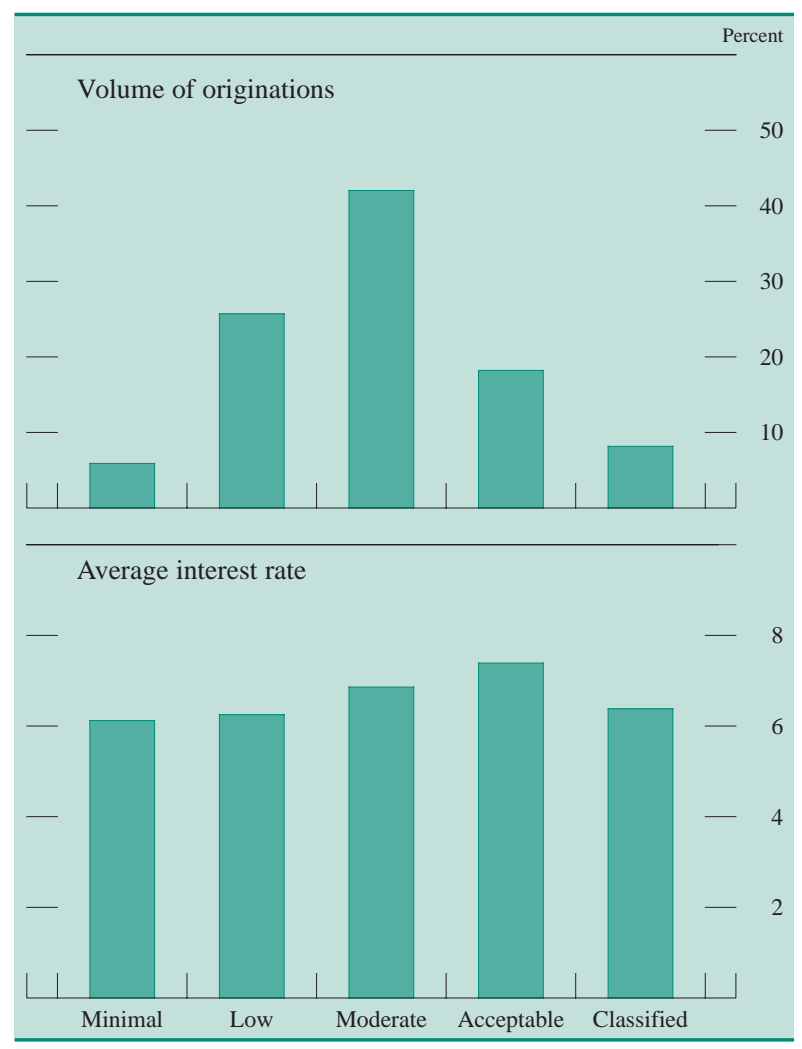

Note. See the appendix for definitions of the risk ratings.
The larger number of categories actively employed by the larger domestic banks and the U.S. branches and agencies of foreign banks could be the result of more detailed internal risk-rating systems at these institutions, which could yield a wider range of ratings in the common system. Alternatively, the larger domestic and foreign institutions may make loans with a greater range of risk than the smaller domestic banks do.

\section{Loan Pricing and Risk Ratings}

The largest percentage of loan originations-more than 40 percent by volume-were classified as having moderate risk (the middle-risk category). Relatively small percentages-less than 10 percent - of loans were reported in the minimal-risk and classified categories (chart 2). About 25 percent of the loans were classified as having low risk, and less than 20 percent were in the acceptable-risk category.

As expected, effective loan rates generally increase on average with risk, although the rate on classified loans (the highest-risk category) is relatively low, perhaps because of the low rates on some workout loans (chart 3). To separate the effect of risk ratings on loan rates from the effects of other loan characteristics, we used multiple regression analysis. Regres-

3. Average interest rate, by type of institution and risk rating, May 1998 STBL

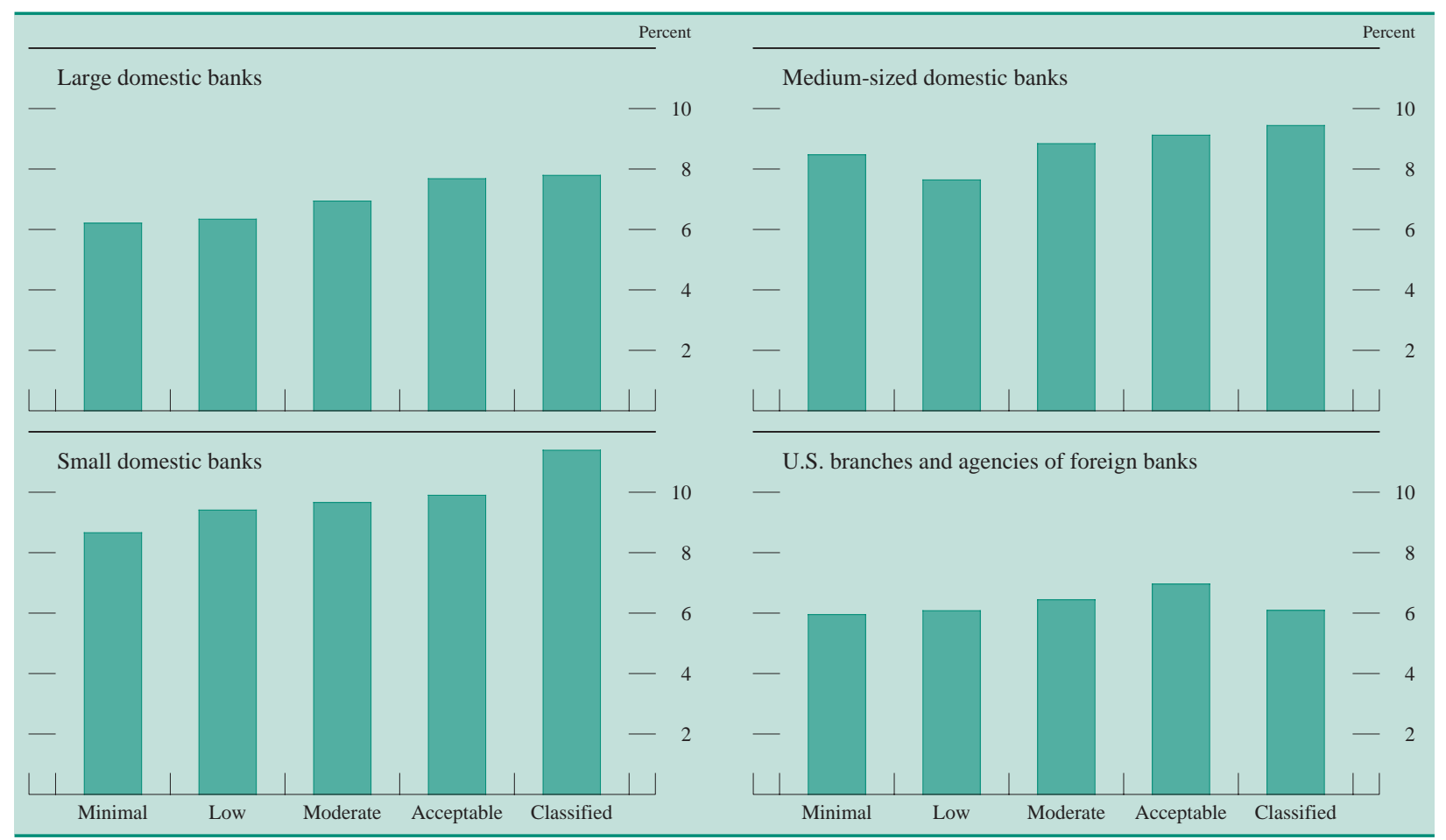

Note. See the general note to table 1 for size definitions and the appendix for definitions of the risk ratings. 
sion results that control for the loan characteristics measured by the survey show that the estimated difference in rates between loans in the minimal-risk category and those in the acceptable-risk category is about 75 basis points-about 50 basis points less than the difference between the average rates on loans in these categories shown in chart 2 (table 3).

The risk premiums indicated by the regression results are roughly in line with yield spreads on rated securities, at least for higher-quality loans. The low- risk category is defined to include loans to firms with BBB-rated debt. Rates on loans in this category are estimated to be 15 basis points higher than those on loans in the minimal-risk category. This spread is somewhat smaller than that between the yields on AA-rated and BBB-rated bonds, but it is similar to the spread between the rates on medium-grade and prime, one-month commercial paper. At the lowerquality end, the estimated premium on loans in the highest-risk category (classified) relative to loans in

3. Coefficients from cross-section regression equations for the effective loan rate, by type of institution, May 1998

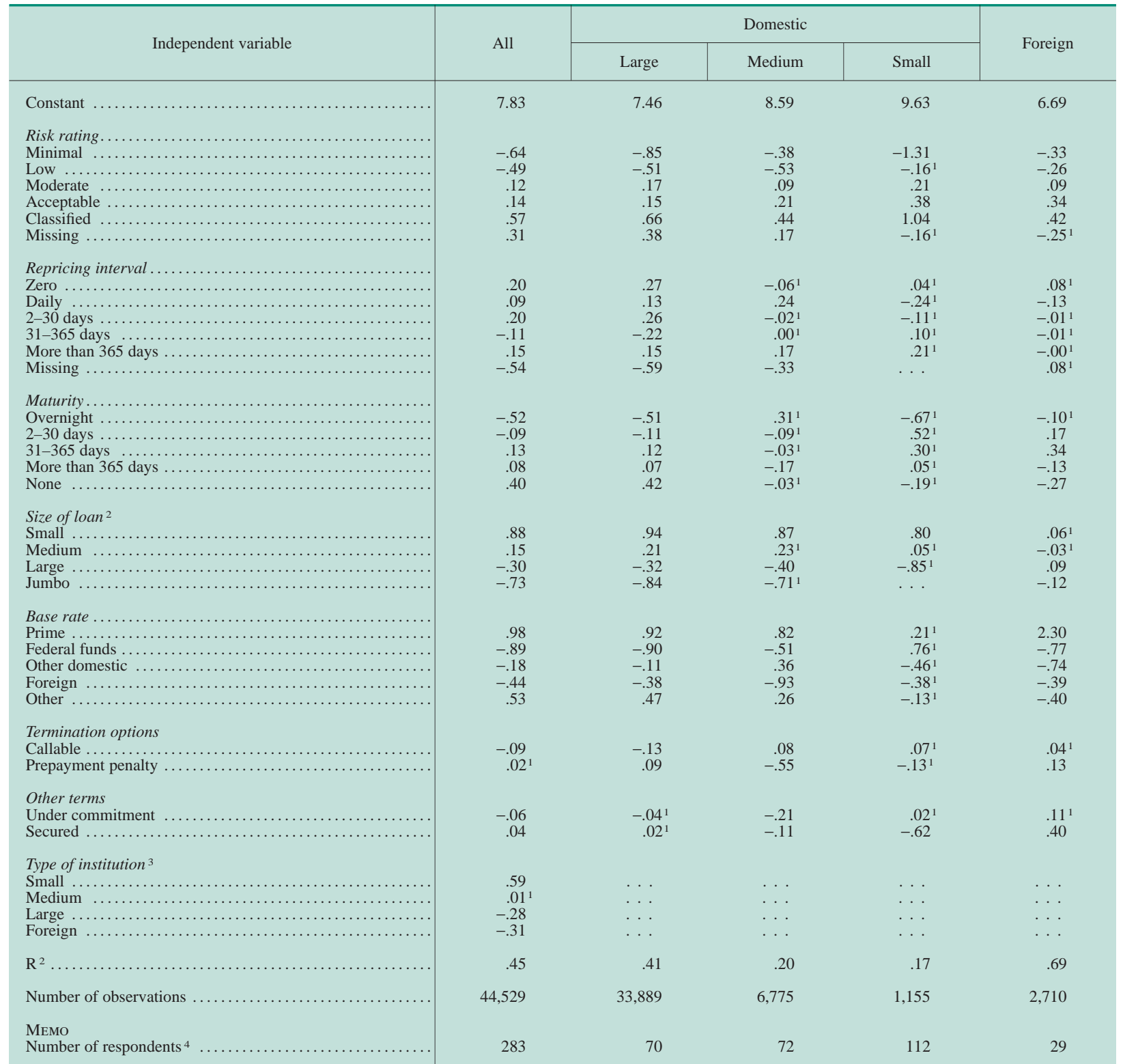

Note. The regressions are unweighted.The coefficients on each set of dummy variables that are exhaustive (risk rating, repricing interval, maturity, size of loan, base rate, and type of institution) are restricted to sum to zero.

1. This coefficient is not statistically significant at the 5 percent level. Unless otherwise noted, the remaining coefficients are significant at that level.

2. The loan size dummy variables are defined as follows: Small loans are those less than or equal to $\$ 100,000$; medium-sized, larger than $\$ 100,000$ but less than or equal to $\$ 1$ million; large, larger than $\$ 1$ million but less than or equal to $\$ 10$ million; and jumbo, larger than $\$ 10$ million.

3. For the definitions of size of bank, see the general note to table 1 .

4. See note 2 to table 2 . 
the lowest-risk category (minimal risk) is 121 basis points. This result is well below the difference in yield between AA-rated bonds and junk bonds at the time of the May survey. This difference may reflect the better protections that bank loans can offer in the event of difficulties, as well as the inclusion of relatively low-interest-rate workout loans in the classified category.

The regression coefficients on the dummy variables for risk ratings indicate that small banks charge the largest rate premiums for increased loan risk while medium-sized banks charge the smallest. Rates on loans rated as having minimal risk and acceptable risk differ by 100 basis points at large domestic banks, 59 basis points at medium-sized banks, and 169 basis points at small banks; at the foreign institutions, this spread is 67 basis points. The coefficients on risk ratings generally rise in step with risk for both the domestic and foreign institutions.

\section{Loan Pricing and Repricing Intervals}

An examination of the distribution by repricing interval of the volume of loan originations in the May survey reveals that loans with a repricing interval of zero (primarily prime-rate-based loans, which by industry practice are subject to repricing at any time) accounted for about 15 percent of the dollar volume of new loans (chart 4). ${ }^{8}$ Because these loans tend to be relatively small, however, they accounted for more than 40 percent of the number of loans originated. Conversely, loans that reprice daily, which tend to be large, accounted for nearly half the dollar volume but only about 15 percent of the number of new loans. Loans with repricing intervals longer than a year accounted for only a small proportion of originations. ${ }^{9}$

The average rate on zero-interval loans, which, as already noted, are typically prime based, is higher than the average rate on loans that reprice every day (chart 4, bottom panel). Aside from prime-based loans, loan rates in the May survey rose on average with the length of the repricing interval. The regres-

8. The repricing interval is the time between the date the loan is made and the next date on which the loan interest rate can change.

9. The distributions reported here are for originations and so are not representative of the outstanding amounts of business loans on banks' books. Loans with shorter maturities will make up a larger share of originations than of outstandings. Repricing intervals and maturities tend to move together (indeed, for fixed-rate loans they are the same), and so the distribution of originations by repricing interval is more heavily weighted toward shorter-interval loans than would be the distribution of outstandings.
4. Distribution of loan originations and average interest rate, by repricing interval, May 1998 STBL

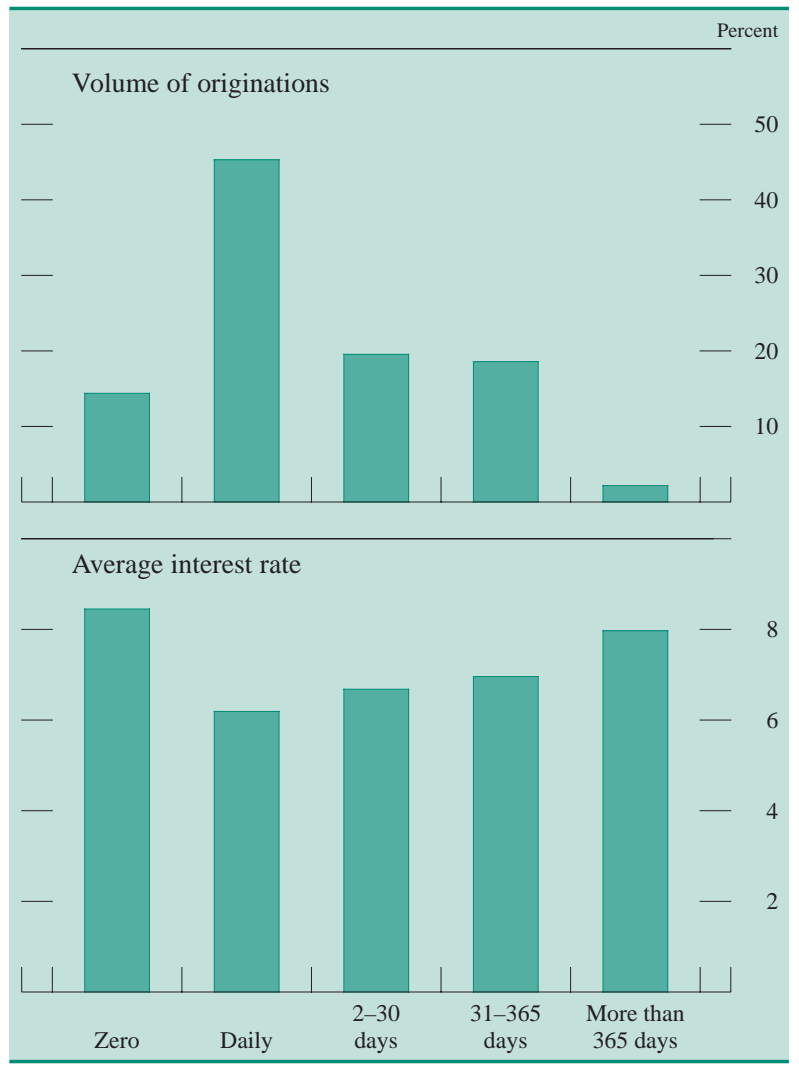

NoTE. Loans with a zero repricing interval can reprice at any time and largely have prime-based rates.

sion results show, however, that once the effects of other loan terms are taken into account, changes in the repricing interval did not have a consistent effect on loan interest rates despite the slight upward tilt to the yield curve during the survey week (table 3 , first column). In part, this apparent lack of influence may reflect imprecise measurement of risk. As noted, the ratings reported on the survey do appear to provide information on banks' assessment of loan risk. However, with only five risk-rating categories, many banks may find it difficult to map their internal ratings into those used for the survey. As a result of these difficulties, some portion of loan risk is likely not accounted for by the risk rating and may be correlated with loan terms. For example, if banks are more willing to make fixed-rate loans with long maturities to low-risk borrowers or to those with highquality collateral, then the regression results for the repricing interval variables may be capturing both the slope of the yield curve and also the lower average risk of those receiving loans with long repricing intervals. 


\section{Termination Options}

During the May survey week about 10 percent of loan originations, by volume, were callable and about 30 percent were subject to a prepayment penalty. Larger loans were more likely to have a prepayment penalty, however; by number, more than 90 percent of the loan originations did not have a penalty. ${ }^{10}$

The regression results suggest little relationship between loan interest rates and termination options. The coefficients on the dummy variables designating loans that can be called and those with prepayment penalties are generally small and of differing signs across the subsamples. Negative coefficients would indicate that lenders were accepting lower loan interest rates in order to obtain the option to call a loan or to restrict the option to repay the loan. However, banks may be more likely to impose these conditions when the borrower has undesirable characteristics that are not fully captured by the risk ratings, resulting in positive or zero coefficients.

\section{Lending Terms at the U.S. Branches and Agencies of Foreign Banks}

The addition of the foreign branches and agencies had a substantial effect on the estimated average terms on new business loans (table 4). The foreignrelated institutions accounted for nearly half of the gross commercial and industrial loan extensions in the survey week-about twice the share of such loans on their books (chart 1). This high proportion reflected the larger average size and shorter average maturity of the loans made by these institutions. The average loan at foreign branches and agencies was more than $\$ 5.8$ million-roughly twelve times the average loan size at domestic banks. The average maturity of new loans at the branches and agencies was 115 days, less than one-third of the average maturity at domestic banks. The loans at branches and agencies were about as likely to be made under commitment, to be secured with collateral, or to be callable but far more likely to have a prepayment penalty than loans at domestic institutions. The aver-

10. Largely because of the infrequency of prepayment penalties, 90 percent of the volume of loans reported by domestic banks on the May 1997 survey should properly have been classified as demand loans under the instructions before the revisions. Only 23 percent of the loans on the February 1997 survey, the last before the survey changes, were reported as demand loans, suggesting that in the past many banks were incorrectly reporting maturities for loans that should have been classified as demand loans.
4. Average loan terms at domestic and foreign institutions, by dollar volume of loan extensions, May 1998

\begin{tabular}{|c|c|c|c|}
\hline Term & All & Domestic & Foreign \\
\hline Size (thousands of dollars) & 805 & 453 & 5,817 \\
\hline Average maturity (days) ... & 269 & 419 & 115 \\
\hline Average repricing interval (days) & 47 & 69 & 22 \\
\hline Percentage secured by collateral & 36.6 & 37.1 & 36.1 \\
\hline \multicolumn{4}{|l|}{ Termination options (percent) } \\
\hline Callable ................... & 11.7 & 13.8 & 9.4 \\
\hline Prepayment penalty $\ldots . . . . . .$. & 31.0 & 9.9 & 53.9 \\
\hline Made under commitment (percent) & 73.5 & 73.3 & 73.6 \\
\hline Average risk rating ${ }^{1} \ldots \ldots \ldots \ldots$ & 2.97 & 2.96 & 2.98 \\
\hline Effective rate (percent) & 6.80 & 7.23 & 6.34 \\
\hline \multicolumn{4}{|l|}{ МЕмо: } \\
\hline Gross extensions (billions of dollars) & 134.7 & 70.7 & 63.9 \\
\hline Number of respondents ${ }^{2} \ldots \ldots \ldots \ldots$ & 283 & 254 & 29 \\
\hline
\end{tabular}

Note. The figures shown are estimates for all domestically chartered commercial banks and U.S. branches and agencies of foreign banks.

1. Risk ratings range from 1 (least risk) to 5 (highest risk). See the appendix for definitions of the rating categories.

2. See note 2 to table 2 .

age risk rating for loans at the foreign-related institutions was about the same as that at domestic banks. Nonetheless, the average loan interest rate was about 90 basis points lower at the branches and agencies. As shown by the coefficient on the dummy variable for foreign institutions (table 3, first column), however, rates at these lenders are similar to those at large domestic banks once the effects of other loan characteristics are taken into account.

\section{CONCLUSION}

The addition to the STBL of an item on loan risk rating provides a unique source of information on the riskiness of new business loans. This information should improve the interpretation of trends in loan pricing and so contribute to the formulation of monetary policy. The information also improves the Federal Reserve's knowledge of banks' use of risk ratings. The addition of U.S. branches and agencies of foreign banks to the survey panel makes the data on loan pricing more comprehensive, and therefore the data should provide better information on loan interest rates and other terms available in the market.

APPENDIX: INSTRUCTIONS FOR THE

REPORTING OF THE NEW ITEMS ON THE

SURVEY OF TERMS OF BUSINESS LENDING

The following excerpts from the STBL instructions are for the items that became part of the survey in May 1997. The new items are the following: the next 
date on which the loan rate may be recalculated, the termination options, and the risk rating. ${ }^{11}$

\section{Next Date on Which the Loan Rate May Be Recalculated}

Enter the first date on which the rate on the loan will be recalculated to reflect changes in the base rate, if any.

For a loan rate that can be recalculated at any time (as with many prime-based loans), enter the date made.

If the interest rate on the loan is fixed for a period less than the maturity of the loan (for example, a loan that matures in 90 days but has a rate that is recalculated every 30 days relative to the 30-day LIBOR), enter the date on which the interest rate can first be recalculated.

If the interest rate is fixed for the life of the loan, enter the loan's date of maturity.

If the interest rate is fixed and the loan has no stated date of maturity, enter " 0. ."

\section{Termination Options}

a. Check "yes" under "Callable" when, according to the terms of the agreement, the lender can call or renegotiate the terms of the loan before maturity. Otherwise, check "no" under "Callable."

Check "no" if the lender's ability to call or renegotiate the loan is contingent on a change in the status of the borrower (for example, an increase in the borrower's debt-equity ratio).

b. Check "yes" under "Prepayment penalty" when the borrower must pay a penalty or fee (sometimes called a "breakage fee") in order to repay or reprice the loan before its scheduled maturity or the next scheduled date on which the rate is recalculated (if any). If there is no such fee or penalty, check "no" under "Prepayment penalty."

\section{Risk Rating}

If your institution assigns internal risk ratings to business loans, enter the numerical designation from the list provided below that most closely matches the definition of the internal rating assigned to this loan.

11. The report form and a complete set of instructions are available on request from the Financial Reports Section, of the Board's Division of Research and Statistics, at 202-452-3829.
Do not enter your institution's own internal risk rating.

If your institution rates loans, but a particular loan is unrated, or not yet rated, enter " 0 " for that loan.

If your institution does not assign internal risk ratings to business loans, either (a) leave this column blank or (b) use the categories presented below to make the assignment.

The definitions provided here take account of both the characteristics of the borrower and the protections provided in the loan contract. Note that the definitions are intended to characterize ranges of risk; hence the definition of your institutions's internal rating for a loan probably will not exactly match any of the provided definitions. Enter the numerical designation that corresponds most closely to the internal rating of your institution.

The risk rating categories provided here are not intended to establish a supervisory standard for the maintenance or reporting of internal risk rating systems.

\section{Minimal Risk (Enter “1”)}

Loans in this category have virtually no chance of resulting in a loss. They would have a level of risk similar to a loan with the following characteristics:

- The customer has been with your institution for many years and has an excellent credit history.

- The customer's cash flow is steady and well in excess of required debt repayments plus other fixed charges.

- The customer has an AA or higher public debt rating.

- The customer has excellent access to alternative sources of finance at favorable terms.

- The management is of uniformly high quality and has unquestioned character.

- The collateral, if required, is cash or cash equivalent and is equal to or exceeds the value of the loan.

- The guarantor, if required, would achieve approximately this rating if borrowing from your institution.

\section{Low Risk (Enter “2”)}

Loans in this category are very unlikely to result in a loss. They would have a level of risk similar to a loan with the following characteristics:

- The customer has an excellent credit history. 
- The customer's cash flow is steady and comfortably exceeds required debt repayments plus other fixed charges.

- The customer has a BBB or higher public debt rating.

- The customer has good access to alternative sources of finance at favorable terms.

- The management is of high quality and has unquestioned character.

- The collateral, if required, is sufficiently liquid and has a large enough margin to make very likely the recovery of the full amount of the loan in the event of default.

- The guarantor, if required, would achieve approximately this rating if borrowing from your institution.

\section{Moderate Risk (Enter “3”)}

Loans in this category have little chance of resulting in a loss. This category should include the average loan, under average economic conditions, at the typical lender. Loans in this category would have a level of risk similar to a loan with the following characteristics:

- The customer has a good credit history.

- The customer's cash flow may be subject to cyclical conditions but is adequate to meet required debt repayments plus other fixed charges even after a limited period of losses or in the event of a somewhat lower trend in earnings.

- The customer has limited access to the capital markets.

- The customer has some access to alternative sources of finance at reasonable terms.

- The firm has good management in important positions.

- Collateral, which would usually be required, is sufficiently liquid and has a large enough margin to make likely the recovery of the value of the loan in the event of default.

- The guarantor, if required, would achieve approximately this rating if borrowing from your institution.

\section{Acceptable Risk (Enter “4”)}

Loans in this category have a limited chance of resulting in a loss. They would have a level of risk similar to a loan with the following characteristics:

- The customer has only a fair credit rating but no recent credit problems.

- The customer's cash flow is currently adequate to meet required debt repayments, but it may not be sufficient in the event of significant adverse developments.

- The customer does not have access to the capital markets.

- The customer has some limited access to alternative sources of finance possibly at unfavorable terms.

- Some management weakness exists.

- Collateral, which would generally be required, is sufficient to make likely the recovery of the value of the loan in the event of default, but liquidating the collateral may be difficult or expensive.

- The guarantor, if required, would achieve this rating or lower if borrowing from your institution.

\section{Special Mention or Classified Asset (Enter "5")}

Loans in this category would generally fall into the examination categories "special mention," "substandard," "doubtful," or "loss." They would primarily be workout loans, as it is highly unlikely that new loans would fall into this category. 